\title{
Kinetic Investigation of Nitroarylation of Pyrrole with 1-Chloro-4- Nitrobenzene Using a New Multi-Site Phase-Transfer Catalyst under Ultrasonic Condition
}

\author{
Selvaraj $\mathbf{V}^{\mathbf{1}}$, Harikumar $\mathrm{K}^{\mathbf{2}}$, Sathiyaraj $\mathbf{M}^{\mathbf{3}}$ and Rajendran $\mathbf{V}^{\mathbf{3}}$ \\ ${ }^{1} P G$ Department of Chemistry, Sri Akilandeswari Women's College, Wandiwash, Tamil Nadu, India \\ ${ }^{2}$ Sri Chandrashekarendra Saraswathi Viswa Maha Vidyalaya University, Kanchipuram, Enathur, Tamil Nadu, India \\ ${ }^{3}$ Department of Chemistry, Pachaiyappa's College for Men, Kanchipuram, Tamil Nadu, India
}

\begin{abstract}
In the present research work, the solid-liquid reaction was successfully carried out in the new synthesized multisite phase-transfer catalyst, namely i.e., 1,3,5-tribenzyl-1,3,5-triethyl-1,3,5-triazinane-1,3,5-triium trichloride(MPTC), and sonication $(40 \mathrm{kHz}, 300 \mathrm{~W})$ to produce the desired product namely 1-(4-nitropheny) pyrrole from pyrrole and 4-nitrochlorobenzene. The selectivity of $\mathrm{N}$-arylation product was obtained under sonication and MPTC. The combination of ultrasound and MPTC resulted in better efficacy as compared to the individual operations. The apparent reaction rate is greatly enhanced and observed to obey the pseudo-first order kinetics. The $\mathrm{k}_{\text {app }}$ value increases with increasing kinetic parameters that is the amount of [MPTC], [substrate], ultrasonication, stirring speed, temperature, etc.
\end{abstract}

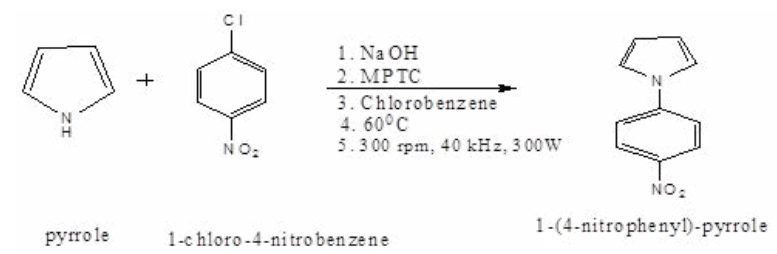

Keywords: Sonochemistry; Pyrrole; Interfacial reaction; Kinetics; MPTC; 1-Chloro-4-Nitrobenzene

\section{Introduction}

As the chemical reactants reside in immiscible phases, phasetransfer catalysts have the ability to carry out the heterogeneous reactions by one of the reactants penetrating from its normal phase (generally aqueous phase) to the organic phase where the reaction take place, which gives a high conversion and selectivity for the desired product under mild reaction conditions [1]. The quaternary onium salts as an effective catalysts for enhancing the two-phase reaction, this methodology occupies an unique niche in organic synthesis and it is a commercially matured discipline with over six hundred applications [2-7] covering a wide spectrum of industries such as pharmaceuticals, agrochemicals, dyes, perfumes, flavours, specialty polymers, pollution control, etc. As the application of phase-transfer catalysts (PTC) grow, much effort was placed on the development of phase - transfer catalysts with higher catalytic efficiency. To this end, researchers have developed "multi-site" phase-transfer catalysts (MPTC) for much higher activity than normal phase-transfer catalysts. Recently, the catalytic behaviour of multi-site phase-transfer catalysts have been attracted much attention, due to the fact that multiple molecules of the aqueous reactant can be carried into the organic phase once a reaction cycle, thus the catalytic efficiency is enhanced [8-12].

Currently, anew analytical and process experimental techniques which are environmental benign techniques viz., ultrasound and microwave irradiation have become immensely popular in promoting various organic reactions [13-17]. Ultrasound irradiation is a transmission of a sound wave through a medium and is regarded as a form of energy enhances the rate of the reaction due to mass transfer and effective mixing [18-20].
The effect of ultrasonic energies in organic syntheses (homogeneous and heterogeneous reactions) has been boosted in recent years [21-27]. Sonication of multiphase systems accelerates the reaction by ensuring a better contact between the different phases $[28,29]$. Further, ultrasound irradiations also increase the reaction rate and avoid the use of high reaction temperatures [30]. These days this environmental benign technology is combined with phase-transfer catalysts (PTC) with primary objective of optimizing reaction conditions [31-33].

Our interest was entered on first time evaluating the influence of ultrasound in association with multi-site phase-transfer catalyst (MPTC) on the synthesis of 1-(4-nitrophenyl) pyrrole from pyrrole with 1-chloro-4-nitrobenzene (CNB) under heterogeneous condition. Since, the kinetic study of nitroarylation of pyrrole using 1-chloro4-nitrobenzene under controlled MPTC reaction conditions will be interesting and challenging, we followed the kinetic studyusing a newly synthesized multi-site phase-transfer catalyst (MPTC) viz., 1,3,5-tribenzyl-1,3,5-triethyl-1,3,5-triazinane-1,3,5-triium trichloride, as a catalyst under ultrasonic condition $(40 \mathrm{kHz} ; 300 \mathrm{~W})$. Further,

${ }^{*}$ Corresponding author: Selvaraj V, Assistant Professor, PG Department of Chemistry, Sri Akilandeswari Women's College, Wandiwash, Tamil Nadu, India-604 408, Tel: +91-44-27268824; E-mail: selvarajptc@gmail.com

Received August 11, 2015; Accepted August 26, 2015; Published September 02, 2015

Citation: Selvaraj V, Harikumar K, Sathiyaraj M, Rajendran V (2015) Kinetic Investigation of Nitroarylation of Pyrrole with 1-Chloro-4-Nitrobenzene Using a New Multi-Site Phase-Transfer Catalyst under Ultrasonic Condition. Chem Sci J 6: 104 doi:10.4172/2150-3494.1000104

Copyright: $\odot 2015$ Selvaraj $\mathrm{V}$, et al. This is an open-access article distributed under the terms of the Creative Commons Attribution License, which permits unrestricted use, distribution, and reproduction in any medium, provided the original author and source are credited. 
to the best of our knowledge, there is no literature reports' regarding nitroarylation of pyrrole under MPTC-ultrasonic irradiation condition.

\section{Experimental}

\section{Chemicals}

The reagents pyrrole, 1-chloro-4-nitrobenzene (CNB), sodium hydroxide, benzene, toluene, chlorobenzene, biphenyl and other reagents are synthesis guaranteed grade (GR) chemicals and were used without further treatments.

\section{Instrumentation}

FT-IR Spectra were recorded on a Brucker-Tensor 27 FT-IR spectrophometer. ${ }^{1} \mathrm{H}$ NMR and ${ }^{13} \mathrm{C}$ spectra were recorded on a Bruker $300 \mathrm{MHz}$ and $75 \mathrm{MHz}$ respective using TMS as an internal standard. Gas chromatography was carried out using a GC-Varian 3700 model Ultrasonic water bath, Equitron, Media Instrument Manufacturing Company, Chennai, India. The ultrasonic generator was a thermostatic bath equipped with dual frequencies $(28 / 40 \mathrm{kHz})$ andelectric power 300 $\mathrm{W}$ with $0.0126 \mathrm{~W} / \mathrm{mL}$ of power density.

\section{Ultrasonic process equipment}

Ultrasonic energy is transmitted to the process vessel through the liquid medium, usually water in the tank. For safety purpose, the sonochemical reactor consisted of two layers stainless steel body. The sonochemical reactor configuration used in the present work is basically an ultrasonic bath. The internal dimension of the ultrasonic cleaner tank is $48 \mathrm{~cm} \times 28 \mathrm{~cm} \times 20 \mathrm{~cm}$ with liquid holding capacity of 5 litres. Two types of frequencies of ultrasound were used in these experiments, which are $28 \mathrm{kHz}$ and $40 \mathrm{kHz}$ with each output as 300 W. Both ultrasounds separately produces through a flat transducer mounted at the bottom of the sonicator. The reactor was a $250 \mathrm{~mL}$ three-necked Pyrex round-bottom flask. This reaction vessel was supported at the centre of the ultrasonic cleaning bath $2 \mathrm{~cm}$ above from the position of the transducer to get the maximum ultrasound energy. All the experimental parameters were done at $40 \mathrm{kHz}$ with output power of $300 \mathrm{~W}$.

\section{Synthesis of 1,3,5-triethyl-1,3,5-triazinane}

A mixture of $83 \mathrm{~g}$ of ethylamine, $40 \mathrm{~g}$ of Para paraldehyde and was placed in a $250 \mathrm{~mL}$ three necked round bottomed Pyrex flask. The reaction was carried out at $30^{\circ} \mathrm{C}$ for 4 hours and was gently refluxed in the nitrogen atmosphere. The solvent was then completely removed under vacuum and we get, i.e., 1,3,5-triethyl-1,3,5-triazane (Scheme 1). The white liquid was stored in a $\mathrm{CaCl}_{2}$ desiccator. Yield: $92 \% ;{ }^{1} \mathrm{H}$ NMR $\left(300 \mathrm{MH}_{\mathrm{Z}} \mathrm{CDCl}_{3}\right) ; \delta .1 .054-1.102\left(\mathrm{t}, 9 \mathrm{H}-\mathrm{CH}_{2}-\mathrm{CH}_{3}\right), 2.449-2.522$ $\left(\mathrm{q}, 6 \mathrm{H}-\mathrm{CH}_{2}-\mathrm{CH}_{3}\right), 3.432\left(\mathrm{~s}, 6 \mathrm{H}, \mathrm{N}^{+}-\mathrm{CH}_{2}\right) \cdot{ }^{13} \mathrm{C} \mathrm{NMR}\left(75 \mathrm{MH}_{\mathrm{z}}, \mathrm{CDCl}_{3}\right): \delta$ $12.62\left(\mathrm{CH}_{2}-\mathrm{CH}_{3}\right), 46.50\left(\mathrm{CH}_{2}-\mathrm{CH}_{3}\right), 73.72\left(\mathrm{~N}^{+}-\mathrm{CH}_{2}\right)$. MS (EI, $\left.70 \mathrm{Ev}, \%\right)$ : $\mathrm{m} / \mathrm{z}$ 171.17; Elemental analysis Calc.: C, $62.98 \% ; \mathrm{H}, 12.16 \% ; \mathrm{N}, 24.23$; Found, C, 63.11\%; H, 12.36\%; N, 24.53 .

\section{Synthesis of MPTC}

A mixture of $8.7 \mathrm{~g}(50.7 \mathrm{mmol})$ of 1,3,5-triethyl-1,3,5-triazane,25 $\mathrm{mL}$ of benzyl chloride, and $75 \mathrm{~mL}$ of ethanol was placed in a $250 \mathrm{~mL}$ three necked round bottomed Pyrex flask. The reaction was carried out at $40^{\circ} \mathrm{C}$ for 24 hours and was gently refluxed in the nitrogen atmosphere. The solvent was then completely removed under vacuum and onium salt, i.e., 1,3,5-tribenzyl-1,3,5-triethyl-1,3,5-triazinane1,3,5-triium trichloride, (MPTC; Scheme 2) was washed with n- hexane $(3 \times 20 \mathrm{~mL})$. The white solid MPTC was stored in $\mathrm{CaCl}_{2}$ desiccators.

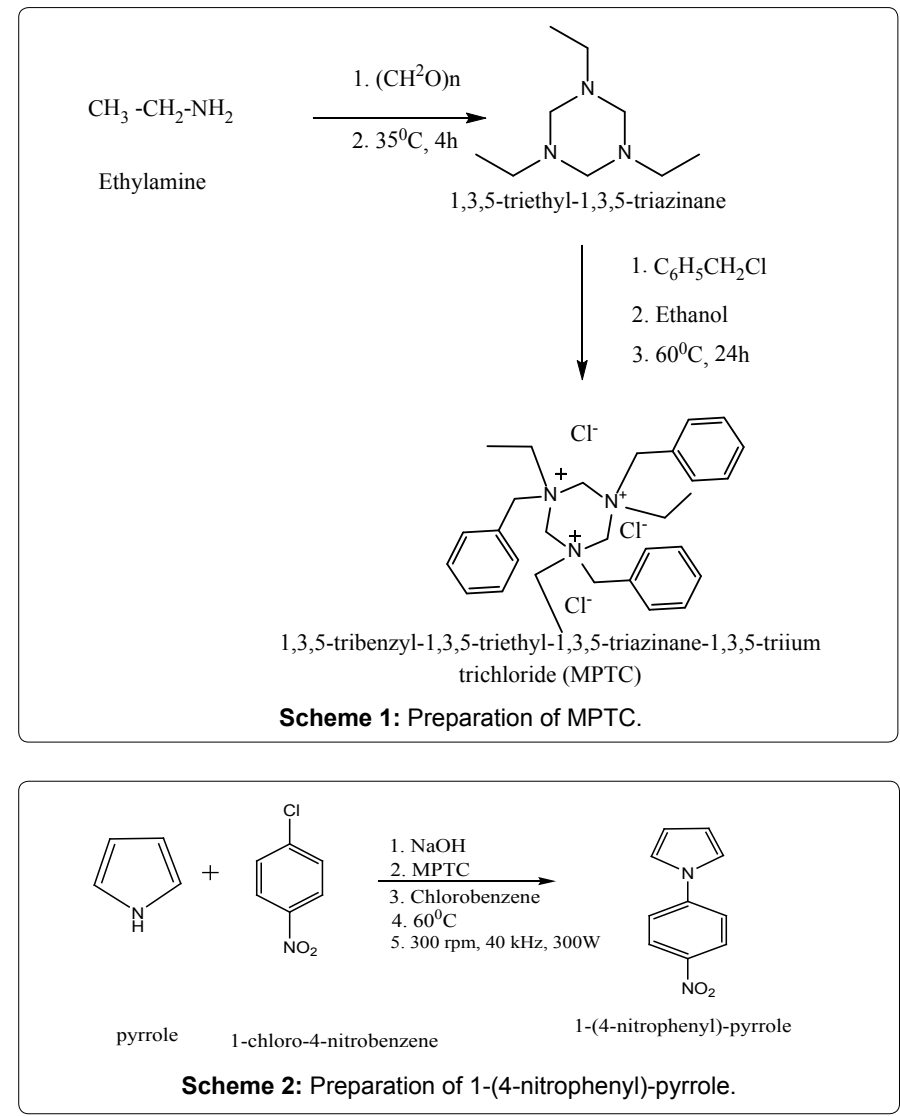

m.p. $182^{\circ} \mathrm{C}$; Yield: $94 \%$; ${ }^{1} \mathrm{H}$ NMR (300 $\left.\mathrm{MH}_{\mathrm{Z}} \mathrm{CDCl}_{3}\right)$; $\delta .1 .403-1.451$ (t,9H- $\left.\mathrm{CH}_{2}-\mathrm{CH}_{3}\right), 2.960-3.024\left(\mathrm{q}, 6 \mathrm{H}-\mathrm{CH}_{2}-\mathrm{CH}_{3}\right), 4.140\left(\mathrm{~s}, 6 \mathrm{H}-\mathrm{Ar}-\mathrm{CH}_{2}\right)$, $5.203\left(\mathrm{~s}, 6 \mathrm{H}, \mathrm{N}^{+}-\mathrm{CH}_{2}\right), 7.345-7.666(\mathrm{~m}, 15 \mathrm{H}, \mathrm{ArH}) ;{ }^{13} \mathrm{C} \mathrm{NMR}\left(75 \mathrm{MH}_{\mathrm{z}}\right.$, $\left.\mathrm{CDCl}_{3}\right): \delta 50.40\left(\mathrm{Ar}-\mathrm{CH}_{2}\right), 66.18\left(\mathrm{~N}^{+}-\mathrm{CH}_{2}\right), 41.92\left(\mathrm{CH}_{2}-\mathrm{CH}_{3}\right), 11.22$ $\left(\mathrm{CH}_{2}-\mathrm{CH}_{3}\right), 128.98,129.41,130.51,131.36$ (Ar-C). Elemental analysis Calc. C, 65.19\%; H, 7.28\%; N, 7.02\%; Found, C, 65.39\%; H, 7.68\%; N, $7.62 \%$.

\section{Synthesis of 1-(4-nitrophenyl) pyrrole under mechanical stirring}

To the mixture of $\mathrm{NaOH}(20 \mathrm{~g})$ in water $(15 \mathrm{~mL})$ and the newly synthesized MPTC $(0.3 \mathrm{~g})$, pyrrole $(1.0 \mathrm{~g}, 0.0152 \mathrm{~mol})$ was added under overhead stirring to generate the pyrrole anion. Then 1-chloro4-nitrobenzene $(2.0 \mathrm{~g}, 0.0127 \mathrm{~mol})$ in chlorobenzene $(40 \mathrm{~mL})$ was added slowly. The reaction mixture was heated at $60^{\circ} \mathrm{C}$ for 6 hours with vigorous stirring. The crude product was isolated by simple extraction with diethyl ether $(3 \times 25 \mathrm{~mL})$. The organic layer was collected and the solvent was evaporated under reduced pressure. The crude product was chromatography $\left(\mathrm{SiO}_{2}\right)$ employing hexane: ethyl acetate (9:1) as an eluent to obtain a pure monoderivative. The identity of the product was confirmed by ${ }^{1} \mathrm{H}$ NMR and ${ }^{13} \mathrm{C}$ NMR spectra of the product. $\mathrm{mp} 182^{\circ} \mathrm{C}$; Yield: 92\%; ${ }^{1} \mathrm{H}$ NMR $\left(300 \mathrm{MH}_{\mathrm{Z}}, \mathrm{CDCl}_{3}\right): \delta 8.288-8.318(\mathrm{t}, 2 \mathrm{H} \mathrm{Ar}-\mathrm{H})$, $7.497-7.526$ (t, 2H Ar-H), 7.176 - 7.182 (d, 2H, Pyrrole-H).6.426-6.432 (d, 2H, Pyrrole-H). ${ }^{13} \mathrm{C}$ NMR $\left(75 \mathrm{MH}_{\mathrm{Z}}, \mathrm{CDCl}_{3}\right): \delta .112 .55,125.59$ (Pyrrole-CH). 119.09, 119.42, 144.73,145.24 (Ar-CH).

\section{Reaction mechanism and kinetic model}

For synthesizing 1-(4-nitrophenyl) pyrrole compound, the overall reaction of pyrrole and 1-chloro-4-nitrobenzene (CNB) was catalyzed by the newly prepared MPTC $\left(\mathrm{Q}^{+} \mathrm{Cl}\right)$ in the aqueous alkaline $(\mathrm{NaOH})$ 
bi-phase medium and is represented in Scheme 2. The reaction is carried out under MPTC assisted ultrasonic irradiation condition $(40 \mathrm{kHz}, 300$ W) under pseudo first-order condition. In the current investigation the kinetics was followed in the presence of an excess amount of pyrrole and by fixing 1-chloro-4-nitrobenzene as limiting agent. The main reason for investigating this reaction is, the effect of low frequency ultrasound irradiation $(40 \mathrm{kHz}, 300 \mathrm{~W})$ along with agitation speed $(300 \mathrm{rpm})$ to find out the effect of change of $\mathrm{k}_{\text {app }}$ value of this system.

\section{Definition}

The conversion $(\mathrm{X})$ of 1-chloro-4-nitrobenzene $(\mathrm{CNB})$ is defines as follows:

$$
\mathrm{X}=1-\left\{[\mathrm{CNB}]_{0} /[\mathrm{CNB}]_{.0, i}\right\}
$$

Where $[\mathrm{CNB}]_{0}$ and $[\mathrm{CNB}]_{\mathrm{oj}}$ represent the concentration of 1-chloro4-nitrobenzene at time $(t) t=0$ and $t>0$, respectively.

\section{Rate expression}

The rate expression for this reaction may be expressed as;

$$
-\mathrm{r}_{\mathrm{CNB}}=\mathrm{k}_{\mathrm{app}}[\mathrm{CNB}]_{\mathrm{o}}
$$

Where $\mathrm{k}_{\text {app }}$ is the apparent reaction rate constant. This reaction is carried out in a batch reactor, so the diminution rate of CNB with time (t) can we expressed as

$$
-\mathrm{d}[\mathrm{CNB}]_{0} / \mathrm{dt}=-\mathrm{r}_{\mathrm{CNB}}=\mathrm{k}_{\mathrm{app}}[\mathrm{CNB}]_{\mathrm{o}}
$$

on integrating the Eq. (3) yields:

$$
-\ln \left\{[\mathrm{CNB}]_{0} /[\mathrm{CNB}]_{., \mathrm{i}}\right\}=-\ln (1-\mathrm{X})=\mathrm{k}_{\mathrm{app}}
$$

Using Eq. (4), we can get the $\mathrm{k}_{\text {app }}$ value experimentally by plotting $-\ln (1-\mathrm{X})$ against time, $(\mathrm{t})$.

\section{Results and Discussion}

The reaction was conducted on a $250 \mathrm{~mL}$ three-necked Pyrex round-bottom flask which permits agitating the solution, inserting the water condenser to recover organic reactant and taking samples and feeding the reactants. This reaction vessel was supported at the centre of the sonicator. A known quantity of chlorobenzene $(30 \mathrm{~mL}$, solvent), sodium hydroxide ( $20 \mathrm{~g} \mathrm{wt} \%$ ), $0.2 \mathrm{~g}$ biphenyl IS,(internal standard) were introduced into the reactor. Then, $1.0 \mathrm{~g}$ of pyrrole $(0.0152 \mathrm{~mol})$ and $2.0 \mathrm{~g}$ of 1-chloro-4-nitrophenol $(0.0127 \mathrm{~mol}), 0.3 \mathrm{~g}$ of the newly synthesized MPTC (with respect to 1-chloro-4-nitrophenol, limiting reagent) were introduced to the reactor to start the reaction. The reaction mixture was stirred at $300 \mathrm{rpm}$. The phase separation was almost immediate on arresting the stirring process. Samples were collected from the organic layer of the mixture (by stopping the stirring for 20-30 seconds each time) at regular time intervals. A pinch of anhydrous $\mathrm{CaCl}_{2}$ was placed in the sample vials to absorb any moisture present in the organic layer. Each run consisted of six samples taken over the period ranging from 5 to 30 minutes. The kinetics was followed by estimating the amount of 1-chloro-4-nitrobenzene (limiting reagent) that disappeared using a gas Chromatography (GC-Varian 3700 model). The analyzing conditions were as follows; Column, $30 \mathrm{~m} \times 0.525 \mathrm{~mm}$ i.d. capillary column containing $100 \%$ poly(dimethyl siloxanen); injection temperature, $250^{\circ} \mathrm{C}$; FID detector $\left(300^{\circ} \mathrm{C}\right)$. Yields were determined from standard curve using biphenyl as an internal standard.

\section{Combined effect of ultrasound and mechanical stirring on the reaction}

To ascertain the influence of agitation speed on the rate of nitroarylation of pyrrole, the speed of agitation was varied in the range of 50-500 rpm along with ultrasound irradiation $(40 \mathrm{kHz}, 300$ W) using 1,3,5-tribenzyl-1,3,5-triethyl-1,3,5-triazinane-1,3,5-triium trichloride(MPTC). The result indicates that the rate of the reaction increases linearly as the agitation speed increases from 50 to $300 \mathrm{rpm}$ (Figure 1). However, on further increasing the agitation speed from 300 to $500 \mathrm{rpm}$, there is no significant improvement in the reaction rate constant. This is because the interfacial area per unit volume of dispersion increased linearly with increasing the stirring speed till 300 $\mathrm{rpm}$ is reached, where there is no significant increase in the interfacial area per unit volume of dispersion with the corresponding increase in the speed. Therefore, the agitation speed was set at $500 \mathrm{rpm}$ for studying the reaction phenomena from which the resistance of mass transfer stays at a constant value [34-42]. The $\mathrm{k}_{\text {app }}$ values are evaluated from the linear plot of $-\ln (1-\mathrm{X})$ versus time. The results indicate that the mechanical effects brought up by the use of low frequency ultrasounds are responsible of the enhancement of the kinetics by harsh mixing, enhancement of mass transfer and so on further, when the same reaction was carried out in the absence of ultrasound, the observed $\mathrm{k}_{\text {ap }}$ value $\left(0 \mathrm{kHz}\right.$, silent condition: $\left.\mathrm{k}_{\text {app }}=7.98 \times 10^{-3}, \mathrm{~min}^{-1}\right)$ almost five fold lesser than in the presence of ultrasonication $\left(40 \mathrm{kHz}, 300 \mathrm{~W}: \mathrm{k}_{\mathrm{app}}=27.92\right.$ $\left.\times 10^{-3}, \mathrm{~min}^{-1}\right)$.

\section{Effect of the amount of newly prepared MPTC}

Experiments were conducted by varying the amount of the newly synthesized MPTC viz., 1,3,5-tribenzyl-1,3,5-triethyl-1,3,5-triazinane1,3,5-triium trichlorideby keeping other experimental parameters are kept constant. The influence of the amount of MPTC on the nitroarylation of pyrrole has been studied by varying amount of MPTC from $0.1 \mathrm{~g}$ to $0.5 \mathrm{~g}$ with respect to 1-chloro-4-nitrobenzene under ultrasound irradiation $(40 \mathrm{kHz}, 300 \mathrm{~W})$. Apparent rate constants were evaluated from the plot of $-\ln (1-\mathrm{X})$ versus time. As shown in Figure 2 , the rate of the reaction increased with increasing in the amount of MPTC along with ultrasound irradiation $(40 \mathrm{kHz}, 300 \mathrm{~W})$. The $\mathrm{k}$ values are linearly dependent on the amount of multi-site phase-transfer catalyst. The increasing the $\mathrm{k}_{\text {app }}$ value is attributed to the synergic effect of ultrasound might be enlarged $[34,43]$.

\section{Effect of the concentration of 1-chloro-4-nitrobenzene}

To investigate the influence of 1-chloro-4-nitrobenzene (CNB) on the kinetics of synthesis of 1-(4-nitrophenyl) pyrrole under ultrasonic

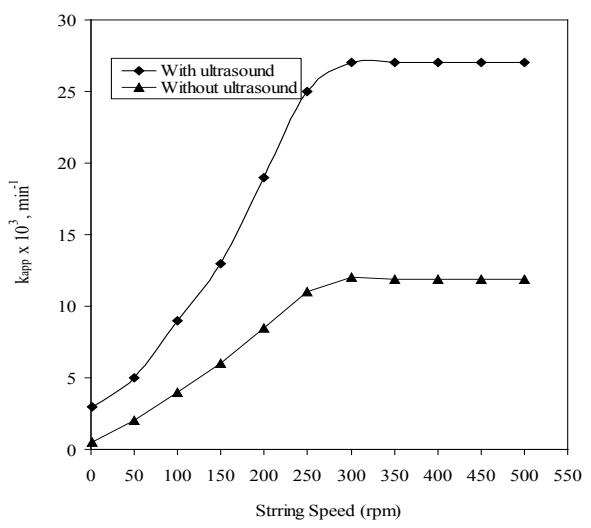

Figure 1: Effect of stirring speed. Plot of the apparent rate constant versus various stirring speeds: $1 \mathrm{~g}$ of pyrrole $20 \mathrm{~g}$ of $\mathrm{NaOH}, 15 \mathrm{~mL}$ of $\mathrm{H} 2 \mathrm{O}, 0.2 \mathrm{~g}$ of internal standard (biphenyl), $2.0 \mathrm{~g}$ of 1-chloro-4-nitrobenzene, $0.3 \mathrm{~g}$ of MPTC, $30 \mathrm{~mL}$ of chlorobenzene, $300 \mathrm{rpm}, 60^{\circ} \mathrm{C}$; ultrasound conditions (40 $\mathrm{kHz}, 300 \mathrm{~W}$ ). 


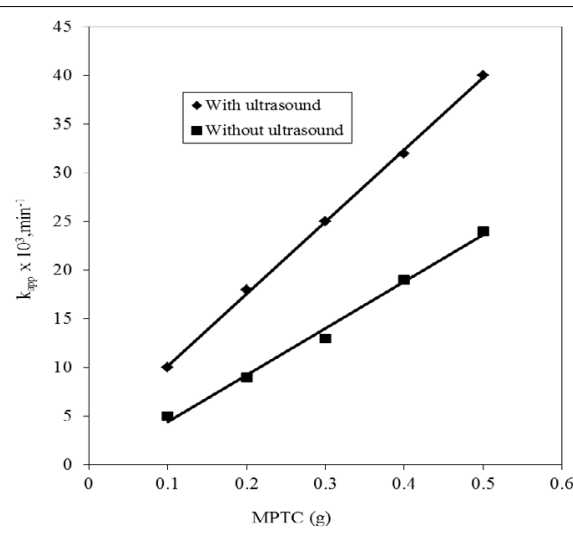

Figure 2: Effect of MPTC. Effect of the amount of MPTC on the apparent rate constant: $1 \mathrm{~g}$ of pyrrole, $20 \mathrm{~g}$ of $\mathrm{NaOH}, 15 \mathrm{~mL}$ of $\mathrm{H} 2 \mathrm{O}, 0.2 \mathrm{~g}$ of internal standard (biphenyl), $2.0 \mathrm{~g}$ of 1-chloro-4-nitrobenzene, $30 \mathrm{~mL}$ of chlorobenzene, $300 \mathrm{rpm}$, $60^{\circ} \mathrm{C}$; ultrasound conditions $(40 \mathrm{kHz}, 300 \mathrm{~W})$.

\begin{tabular}{|c|c|c|}
\hline $\begin{array}{l}\text { 1-chloro-4- } \\
\text { nitrobenzene } \\
\text { (CNB), g }\end{array}$ & $\begin{array}{c}k_{\text {app }} \times 10^{3}, \min ^{-1} \\
\text { (With ultrasound, } 40 \mathrm{kHz} \text {, } \\
300 \mathrm{~W} \text { ) }\end{array}$ & $\begin{array}{c}\mathbf{k}_{\mathrm{app}} \times 10^{3}, \mathrm{~min}^{-1} \\
\text { (Without ultrasound) }\end{array}$ \\
\hline 1.0 & 18.68 & 4.08 \\
\hline 1.5 & 22.44 & 5.66 \\
\hline 2.0 & 27.92 & 7.98 \\
\hline 2.5 & 32.82 & 8.02 \\
\hline 3.0 & 37.41 & 9.22 \\
\hline
\end{tabular}

Table 1: Effect of the amount of 1-chloro-4-nitrobenzene. Effect of amount of 1-chloro-4-nitrobenzene $(\mathrm{CNB})$ on the rate of nitroarylation of pyrrole under ultrasonic condition: $20 \mathrm{~g}$ of $\mathrm{NaOH}, 15 \mathrm{~mL}$ of $\mathrm{H}_{2} \mathrm{O}, 0.2 \mathrm{~g}$ of internal standard (biphenyl), $0.3 \mathrm{~g}$ of MPTC, $30 \mathrm{~mL}$ of chlorobenzene, $300 \mathrm{rpm}, 60^{\circ} \mathrm{C}$; ultrasound conditions $(40 \mathrm{kHz}, 300 \mathrm{~W})$.

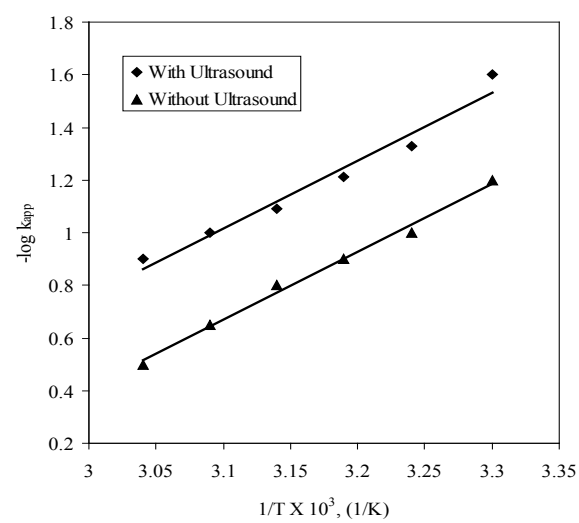

Figure 3: Arrhenius plot. $1 \mathrm{~g}$ of pyrrole, $20 \mathrm{~g}$ of $\mathrm{NaOH}, 15 \mathrm{~mL}$ of $\mathrm{H}_{2} \mathrm{O}, 0.2$ $\mathrm{g}$ of internal standard (biphenyl), $2.0 \mathrm{~g}$ of 1 -chloro-4-nitrobenzene, $0.3 \mathrm{~g}$ of MPTC, $30 \mathrm{~mL}$ of chlorobenzene, $300 \mathrm{rpm}, 60^{\circ} \mathrm{C}$; ultrasound conditions (40 $\mathrm{kHz}, 300 \mathrm{~W}$ ).

irradiation condition $(40 \mathrm{kHz}, 300 \mathrm{~W})$, the amount of $\mathrm{CNB}$ was varied from $1.0 \mathrm{~g}$ to $3.0 \mathrm{~g}$. In the presence and absence of ultrasound results are shown in Table 1 . The data clearly indicates that the $\mathrm{k}_{\text {app }}$ value increases with increasing the amount of CNB. When the 1-chloro-4nitrobenzene concentration increased, the probability of finding the substrate with active-site of the catalyst and ultrasound enhanced the rate of the reaction [33-37]. It may be due to reduces the surface area between the aqueous and organic phases, and hence more reactants collide to each other simultaneously we get higher $\mathrm{k}_{\text {app }}$ value.

\section{Effect of temperature}

The effect of temperature on the reaction between pyrrole and 1-chloro-4-nitrobenzene was studied under otherwise similar conditions. The temperature was varied from 30 to $80^{\circ} \mathrm{C}$. The kinetic profile of the reaction is obtained by plotting -ln (1-X) versus time. It is obvious that the reactivity is increased with an increase in the temperature along with ultrasonic effect [38-42]. The reason is that the number of reactant molecules which possess higher activation energy at a higher temperature and thus the ultrasonic wave easily passes through the reactor [41-44]. The other point is that the collision of the reactants at higher temperature is also increased. Hence, the apparent rate constant is increased at higher temperature. Arrhenius plots were made in Figure 3 of $-\ln \mathrm{k}_{\text {app }}$ against 1/T to get activation energy of 52.16 $\mathrm{kJ} \cdot \mathrm{mol}^{-1}$.

From the literature survey, the dehydrobromination of (2-bromoethyl)benzene catalyzed by tetraoctylammonium bromide (TOAB), an extraction mechanism was proposed [45] due to lower $\mathrm{E}_{\mathrm{a}}$ value $\left(<43 \mathrm{~kJ} \cdot \mathrm{mol}^{-1}\right)$. In general, higher activation energy (more than $43 \mathrm{~kJ} . \mathrm{mol}^{-1}$ ) suggests an interfacial mechanism [44,46]. The activation energy for the heterogeneous ethylation of phenylactonitrile was reported to be $63.64 \mathrm{~kJ} . \mathrm{mol}^{-1}$ and for this an interfacial mechanism was proposed [47]. Further, in the $\mathrm{N}$-alkylation of pyrroleidine-2-one, the Ea (51.35 kJ.mol $\left.{ }^{-1}\right)$ was reported by Sasson and Bilman [48], and for this reaction they proposed an interfacial mechanism. They concluded that the deprotonation of the substrate takes place at the interphase and consequently the organic anion is extracted and reacts in the bulk of the organic phase. The rate-determining step in the process is the anion exchange at the interphase. In our study, the observed $\mathrm{E}_{\mathrm{a}}$ value is 52.36 $\mathrm{kJ} \cdot \mathrm{mol}^{-1}$. Hence, we proposed an interfacial mechanism for our present study [49-52].

\section{Influence of amount of water}

N-Nitroarylation of pyrrole with 1-chloro-4-nitrobenzene (as a limiting agent) under ultrasound condition $(40 \mathrm{kHz}, 300 \mathrm{~W})$ was examined by varying the amount of water from 5 to $25 \mathrm{~mL}$, under standard reaction conditions. Apparent rate constants were obtained from the plot of $-\ln (1-\mathrm{X})$ against time. Generally, the volume of water directly affects both the concentration of sodium hydroxide in the aqueous phase and also generation of anions. Therefore, the conversion (or the reaction rate) will be affected by the volume of water. Figure 4

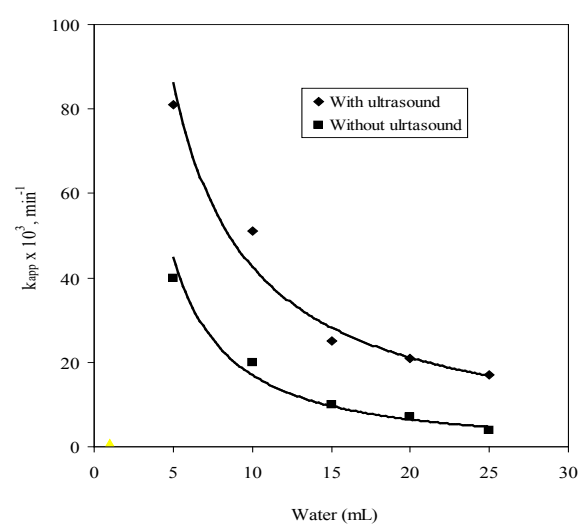

Figure 4: Effect of water. Plot of the apparent rate constants versus different volumes of water; $1 \mathrm{~g}$ of pyrrole, $20 \mathrm{~g}$ of $\mathrm{NaOH}, 15 \mathrm{~mL}$ of $\mathrm{H}_{2} \mathrm{O}, 0.2 \mathrm{~g}$ of internal standard (biphenyl), $2.0 \mathrm{~g}$ of 1-chloro-4-nitrobenzene, $0.3 \mathrm{~g}$ of MPTC, $30 \mathrm{~mL}$ of chlorobenzene, $300 \mathrm{rpm}, 60^{\circ} \mathrm{C}$; ultrasound conditions $(40 \mathrm{kHz}, 300 \mathrm{~W})$. 
shows the effect of the amount of water on the rate of the reaction. On increasing the volume of water, the concentration of alkali compound in aqueous solution is decreases. This situation would dramatically reveal the hydration effect of the active catalyst $\left[\mathrm{N}^{-} \mathrm{Q}^{+}\right]$(Scheme 3$)$ as the volume of water changed from 30 to $50 \mathrm{~mL}$. From the literature, the kinetic study of the phase-transfer catalyzed etherification of 4,4'-bis(chloromethyl)-1,1'-biphenyl with phenol in an alkaline solution of potassium hydroxide/organic solvent two-phase medium, similar decrease in rate of the reaction on corresponding increase in volume of water was reported [53].

\section{Effect of ultrasonic power}

Ultrasonic irradiation is defines as acoustic waves with frequencies in the $20 \mathrm{kHz}-100 \mathrm{MHz}$ range [24-30]. They create cavities generating locally high temperature and pressures [40-43] or strong electric fields [42-45]. Ultrasound is known to accelerate diverse types of organic reactions and it is established generous reactions, which are otherwise slow due to poor mass transfer are accelerated by sonication due to cavitation [41-45]. It has been reported that a combination of PTC and ultrasound is often better than either of the two techniques alone [43-47]. In such transfer of species across the interface and ultrasound merely facilitates this transfer, possibly by increasing the interfacial area across which this transfer occurs.

To ascertain the influence of various ultrasonic frequencies on the rate of nitroarylation of pyrrole with same output power of 300 $\mathrm{W}$, the ultrasonic frequency was varied in the range of 28 and $40 \mathrm{kHz}$ under otherwise similar conditions using MPTC as the catalyst. Also we followed the reaction under silent condition. The kinetic profile of the reaction is obtained by plotting $-\ln (1-\mathrm{X})$ against time. In our experimental condition at 30 minutes, without ultrasonic irradiation (silent condition) the $\mathrm{k}_{\text {app }}$ values is $7.98 \times 10^{-3}, \mathrm{~min}^{-1}$ but in the presence of ultrasonic condition the $\mathrm{k}_{\text {app }}$ values are $13.46 \times$ $10^{-3}, \mathrm{~min}^{-1}$ and $27.92 \times 10^{-3}, \mathrm{~min}^{-1}$ for $28 \mathrm{kHz}(300 \mathrm{~W})$ and $40 \mathrm{kHz}$

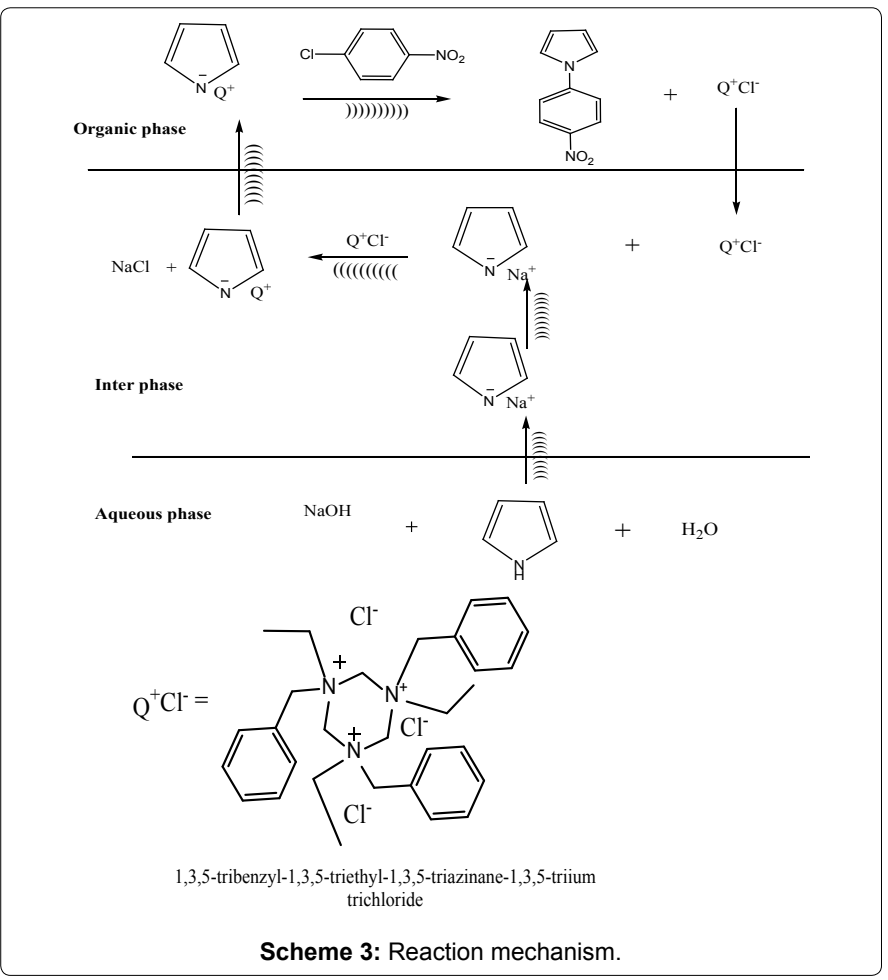

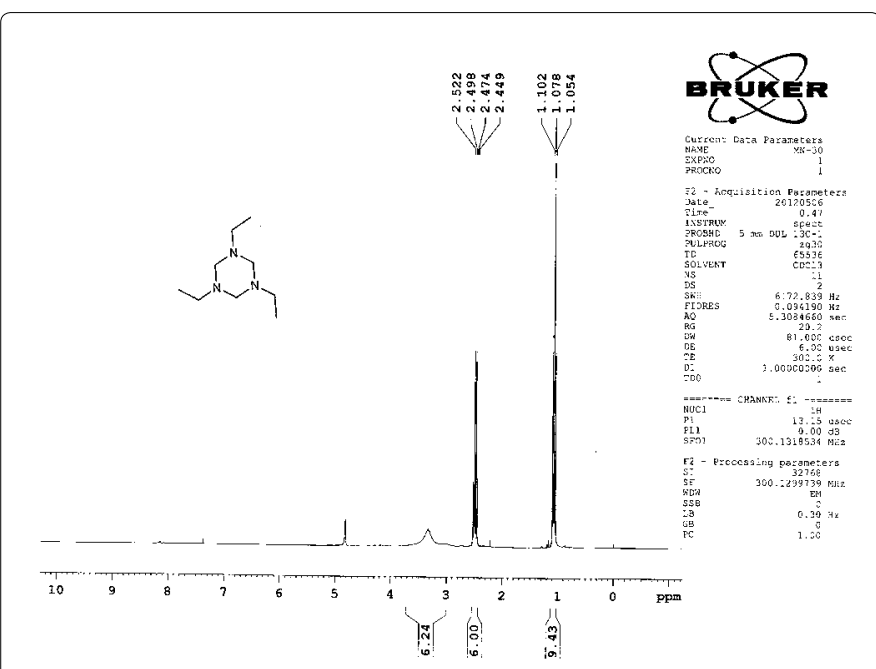

${ }^{1} \mathrm{H}$ NMR of 1,3,5-triethyl-1,3,5-triazane
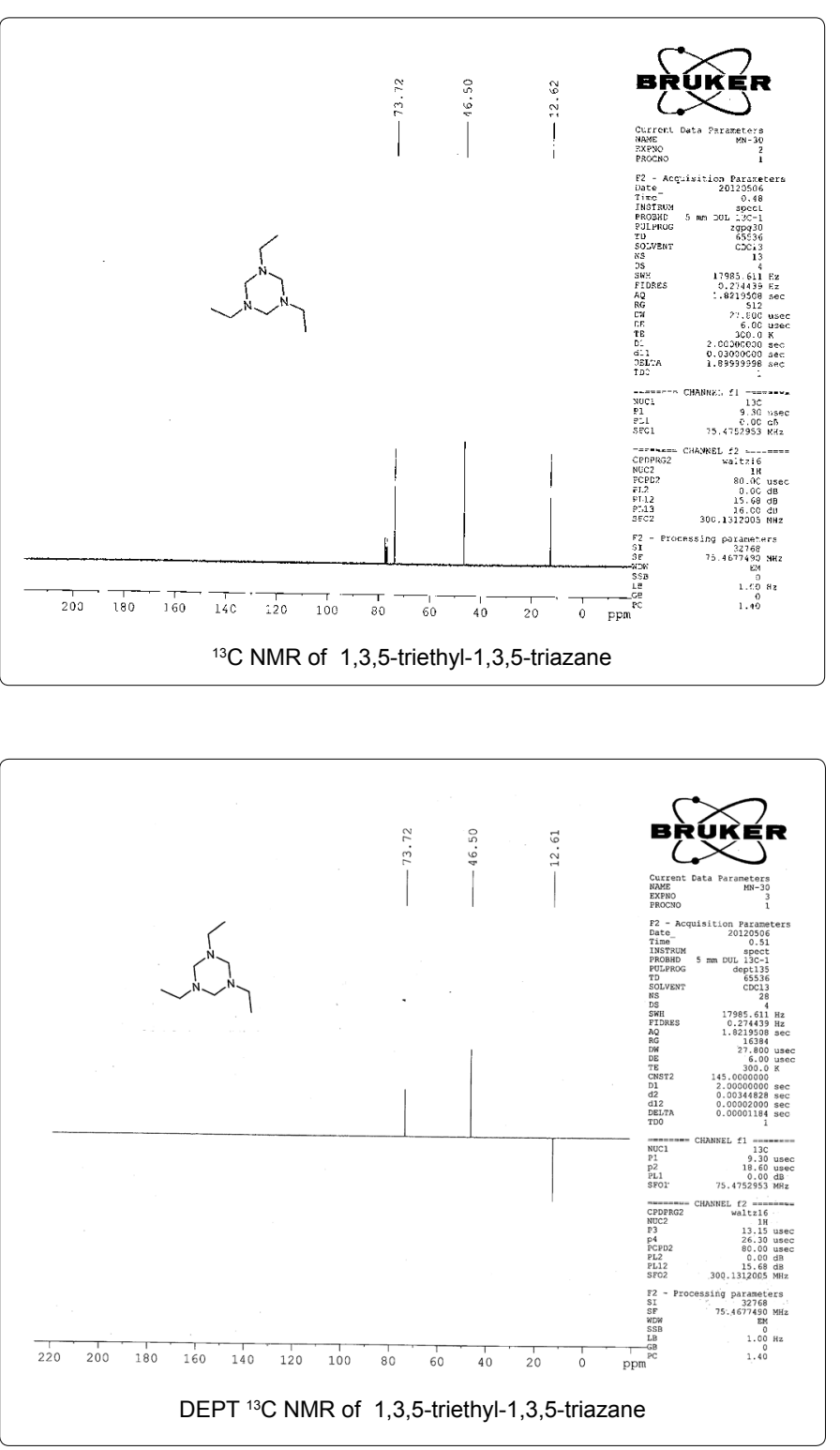


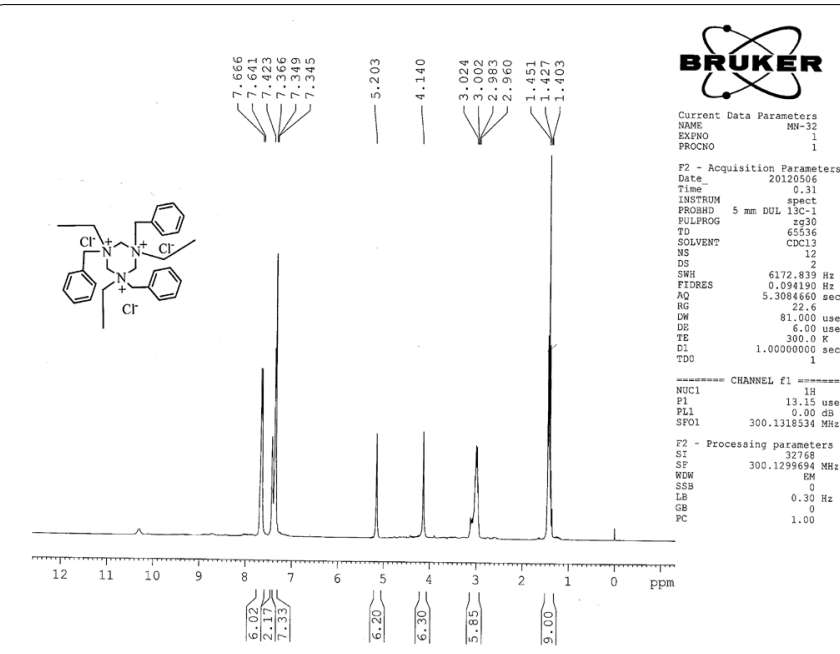

${ }^{1} \mathrm{H} \quad \mathrm{NMR}$ of 1,3,5-tribenzyl-1,3,5-triethyl-1,3,5-triazinane-1,3,5-triium trichloride (MPTC)

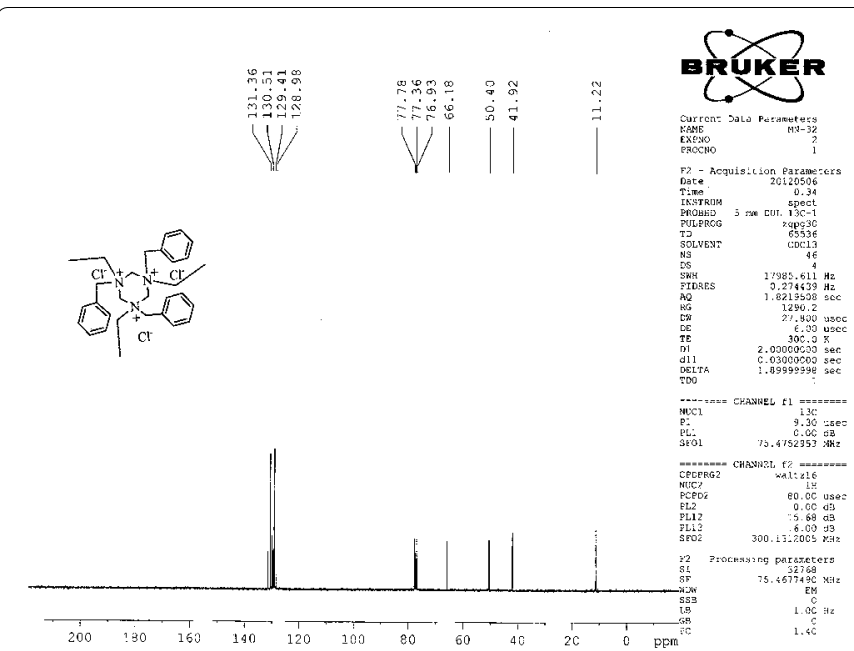

${ }^{13} \mathrm{C}$ NMR of 1,3,5-tribenzyl-1,3,5-triethyl-1,3,5-triazinane-1,3,5-triium trichloride (MPTC)

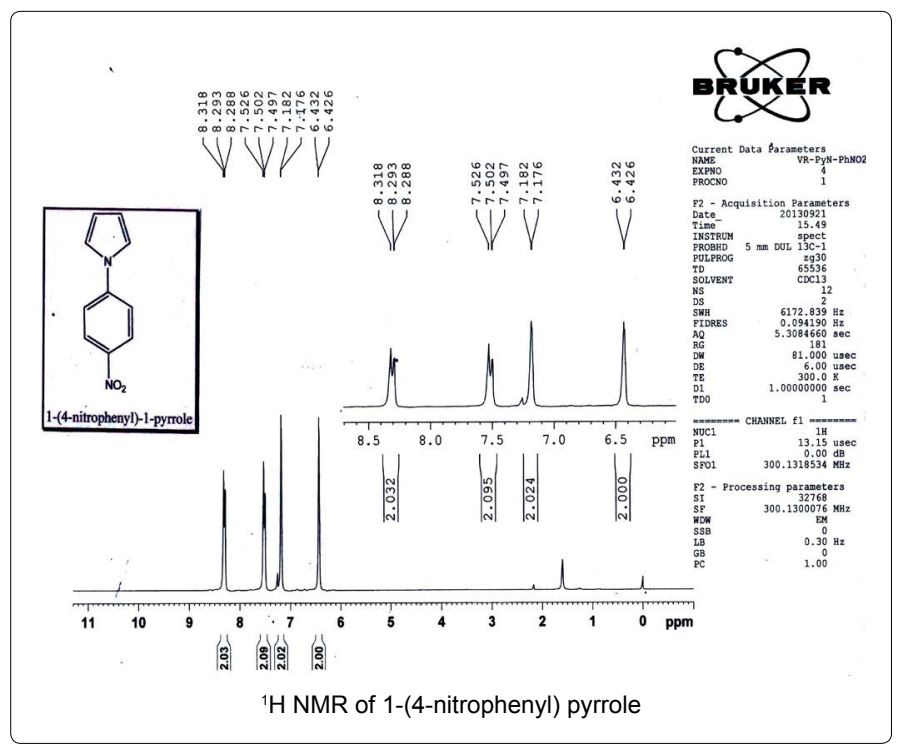

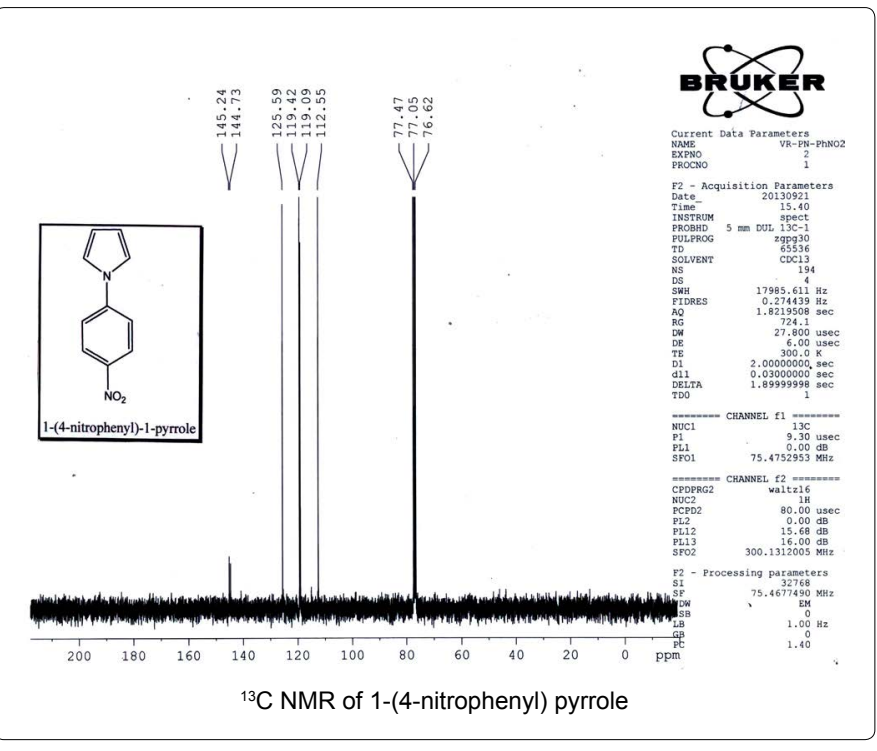

\begin{tabular}{|l|c|c|c|}
\hline Ultrasonic frequency $(\mathrm{kHz}, 300 \mathrm{~W})$ & 0 & 28 & 40 \\
\hline $\mathrm{k}_{\text {app }} \times 103, \mathrm{~min}^{-1}$ & 4.98 & 3.46 & 27.92 \\
\hline
\end{tabular}

Table 2: Effect of ultrasonic frequency. Influence of ultrasonic frequencies on the rate of nitroarylation of pyrrole under ultrasonic condition: $20 \mathrm{~g}$ of NaOH, $15 \mathrm{~mL}$ of $\mathrm{H}_{2} \mathrm{O}, 0.2 \mathrm{~g}$ of internal standard (biphenyl), $0.3 \mathrm{~g}$ of MPTC, $2.0 \mathrm{~g}$, 1-chloro-4nitrobenzene, $30 \mathrm{~mL}$ of chlorobenzene, $300 \mathrm{rpm}, 60^{\circ} \mathrm{C}$.

\begin{tabular}{|l|c|c|c|c|c|}
\hline \multicolumn{5}{|c|}{ Solvents } \\
\hline $\begin{array}{l}\text { Ca (Dielectric } \\
\text { constant) }\end{array}$ & 2.02 & 2.28 & 2.31 & 4.30 & 5.60 \\
\hline $\mathrm{k}_{\text {app }} \times 103, \mathrm{~min}^{-1}$ & & & & & \\
$\left(\begin{array}{l}\text { With ultrasound, } \\
40 \mathrm{kHz}, 300 \mathrm{~W})\end{array}\right.$ & 13.72 & 15.58 & 19.05 & 24.62 & 27.92 \\
\hline $\mathrm{k}_{\text {app }} \times 103, \mathrm{~min}^{-1}$ & & & & & \\
\hline $\begin{array}{l}\text { (Without } \\
\text { ultrasound })\end{array}$ & 2.30 & 3.90 & 4.62 & 5.21 & 7.98 \\
\hline
\end{tabular}

Table 3: Effect of organic solvents. Influence of organic solvents on the rate of nitroarylation of pyrrole under ultrasonic condition: $20 \mathrm{~g}$ of $\mathrm{NaOH}, 15 \mathrm{~mL}$ of $\mathrm{H}_{2} \mathrm{O}, 0.2$ $\mathrm{g}$ of internal standard (biphenyl), $0.3 \mathrm{~g}$ of MPTC, $2.0 \mathrm{~g}$, 1-chloro-4-nitrobenzene, $300 \mathrm{rpm}, 60^{\circ} \mathrm{C}$; ultrasound conditions $(40 \mathrm{kHz}, 300 \mathrm{~W})$.

$(300 \mathrm{~W})$, respectively (Table 2$)$. Hence, the overall $\mathrm{k}_{\text {app }}$ was increased by increasing the ultrasonic frequency in the order of $0 \mathrm{kHz}$ (silent condition) $<28 \mathrm{kHz}(300 \mathrm{~W})<40 \mathrm{kHz}(300 \mathrm{~W})$ for our system. Similar trend was observed by Entezari et al. [46,47].

\section{Effect of organic solvents}

In this work, the influence of various organic solvents on the rate of nitroarylation of pyrrole was followed under otherwise standard reaction conditions. Five organic solvents employed in this study are toluene, anisole, cyclohexane, chlorobenzene, and n-hexane. From the plot of $-\ln (1-\mathrm{X})$ against time, the $\mathrm{k}_{\text {app }}$ values are shown in the Table 3. From the Table 3, chlorobenzene possesses a higher $\mathrm{k}_{\text {app }}$ value among the five organic solvents, due to its higher dielectric constant. In another view the ultrasonic irradiation can enhance the rate in the presence of more polar solvents due to passing higher ultrasonic waves to the reactor and makes fruitful collision between the reactants, and hence we get higher $\mathrm{k}_{\text {app }}$ value for chlorobenzene solvent of this system and also this statement is not always true $[48,49]$. 


\begin{tabular}{|c|c|c|}
\hline $\begin{array}{c}\text { Amount of } \\
\mathbf{N a O H}(\mathbf{g})\end{array}$ & $\begin{array}{c}\mathbf{k}_{\text {app }} \times \mathbf{1 0}^{\mathbf{3}}, \mathbf{m i n}^{-1} \\
\text { (With ultrasound, } \mathbf{4 0} \mathbf{~ k H z}, \\
\mathbf{3 0 0} \mathbf{~ W} \text { ) }\end{array}$ & $\begin{array}{c}\mathbf{k}_{\text {app }} \times \mathbf{1 0}^{3}, \mathbf{m i n}^{-1} \\
\text { (without ultrasound) }^{-1}\end{array}$ \\
\hline 10 & 17.22 & 3.01 \\
15 & 21.91 & 4.22 \\
20 & 27.92 & 7.98 \\
25 & 31.46 & 8.03 \\
30 & 35.33 & 9.71 \\
\hline
\end{tabular}

Table 4: Effect of sodium hydroxide. Influence of alkalinity on $\mathrm{k}_{\text {app }}$ in the nitroarylation of pyrrole under ultrasonic condition: $0.2 \mathrm{~g}$ of internal standard (biphenyl), $0.3 \mathrm{~g}$ of MPTC, $2.0 \mathrm{~g}$, 1-chloro-4-nitrobenzene, $30 \mathrm{~mL}$ of chlorobenzene, $300 \mathrm{rpm}, 60^{\circ} \mathrm{C}$; ultrasound conditions $(40 \mathrm{kHz}, 300 \mathrm{~W})$.

\section{Effect of varying sodium hydroxide concentrations}

In the PTC/base catalyzed reactions, the reaction rate is known to be greatly affected by a concentration of the alkaline compound. The rate of nitroarylation of pyrrole strongly depends on the strength of the sodium hydroxide. Kinetic experiments were carried out, by employing 10 to $30 \mathrm{~g}$ of $\mathrm{NaOH}$ under similar reaction conditions. The Kinetic profile of the reaction is obtained by $-\ln (1-\mathrm{X})$ against time. The $\mathrm{k}_{\mathrm{app}}$ values tremendously increased with increasing in basicity of $\mathrm{OH}^{-}$ion (Table 4). It suggests that the hydroxide ions which are less solvated by water molecules and there by the $\mathrm{k}_{\text {app }}$ value increases [49-51].

\section{Mechanism}

The experimental result from the present kinetic study indicates that the dependencies of the kinetic data on the entire stirring speed, concentration of the catalyst, aqueous sodium hydroxide and temperature and higher $\mathrm{E}_{\mathrm{a}}$ value are indicative of an interfacial mechanism [49-53]. Initially, the hydroxide anion deprotonates pyrrole at the interface, forming an ion-pair $\left(\mathrm{N}^{-} \mathrm{Na}^{+}\right)$. Upon the addition of the catalyst, $\mathrm{Q}^{+} \mathrm{X}$, ion exchange takes place at the interface $\left(\mathrm{N}^{-} \mathrm{Q}^{+}\right)$and the new formed ion pair $\mathrm{N}^{-} \mathrm{Q}^{+}$(Scheme 3 ) which is more organophilicity and hence easily migrates into the organic phase. This ion-pair reacts with the 1-chloro-4-nitrobenzene (CNB) present in the organic phase resulting in the formation of the required product i.e., 1-(4-nitrophenyl) pyrrole.

\section{Conclusion}

In the present study, the rate of the reaction was controlled to study the kinetic aspects of the formation of the 1-(4-nitrophenyl) pyrrole from pyrrole and 1-chloro-4-nitrobenzene under ultrasonicMPTC condition. The apparent reaction rates were observed to obey the pseudo-first order kinetics, performing the reaction in ultrasonic condition resulted in shorter reaction time, selectivity, high yield, etc. The reaction mechanism and the apparent rate constants were obtained from the experimental results, the apparent rate constants are found to be directly dependent on each kinetic variables, viz., [MPTC], $[\mathrm{NaOH}]$, ultrasonic frequency, stirring speed and temperature. However it decreases with increase in volume of water. Energy of activation was calculated from the Arrhenius plot. Based on the experimental evidence, an interfacial mechanism has been proposed. Combination of ultrasound and MPTC resulted in better efficacy as compared to the individual operations.

\section{Acknowledgments}

The authors would like to thank Sri Akilandeswari Women's College, Wandiwash, Tamil Nadu, India for their grant and permission to do this research work.

\section{References}

1. Yadav GD (2004) Insight into green phase - transfer catalysis. Top Catal 29: 145-161.
2. Witula T, Holmberg $K$ (2005) Use of a mesoporous material for organic synthesis. Langmuir 21: 3782-3785.

3. Yang Z, Zhou H, Ji H (2012) Mechanism into selective oxidation of cinnamaldehyde using beta-cyclodextrin polymer as phase-transfer catalyst. Tetrahedron 68: 5912-5919.

4. Shiri M, Zolfifgol MA (2009) Surface-type Catalysts in organic reactions. Tetrahedron 65: 587-598.

5. Mingqiang L, Xigao J (2005) Heteropoly Blue as a Reaction-controlled phasetransfer catalyst for the Epoxidation of olefins. Bull Chem Soc Jpn 78: 15751579 .

6. Jose N, Sengupta S, Basu JK (2009) Selective production of benzaldehyde by permanganate oxidation of benzyl alcohol using 18-crown-6 as phase-transfer catalyst. J Mol Catal A: Chemical 309: 153-158.

7. Jin G, Ido T, Goto S (2001) Effect of third-phase properties on benzyl-n-butyl ether synthesis in phase-transfer catalytic system. Catalysis Today 64: 279-287.

8. Vivekanand PA, Balakrishnan T (2009) Superior catalytic efficiency of a new multi-site phase-transfer catalyst in the c-alkylation of dimedone-a kinetic study. Catal Commun 10: 1371-75.

9. Ali HE (2007) Cycloalkylation reaction of fatty amines with a alpha-dihaloalkanes role of bis-quaternary ammonium salts as phase-transfer catalysts. Catal Commun 8: 855 .

10. Sankar K, Rajendran V (2012) Ultrasound assisted free radical polymerization of glycidyl methacrylate by a new disite phase-transfer catalyst system- A kinetic study. Ultrason Sonochem 19: 1205-1212.

11. Yang YM, Lin DW (2011) Third-liquid phase-transfer catalysed esterification of sodium benzoate with novel dual-site phase-transfer catalyst under ultrasonic irradiation. Catal Commun 14: 101-106.

12. Li CJ (1996) Acqueous barbier-grignard type reaction; scope, mechanism and synthetic applications. Tetrahedron 52: 5643-5668.

13. Loupy A, Petit A, Hamelin J, Boullet FT, Jacquault P, et al. (1998) New solventfree organic synthesis using focused microwaves. Synthesis 1213-1234.

14. Lemoine S, Thomazeau C, Joannard D, Trombotto S, Descotes G, et al (2000) Sucrose tricarboxylate by sonocatalysed TEMPO-mediated oxidation. Carbohydr Res 326: 176-184

15. Luzzio FA Moore WJ (1993) Ultrasound in oxochromium(VI)-mediated transformations. Ultrasound-mediated preparation and applications of chromyl chloride. J Org Chem 58: 512-515.

16. Luche JL (1997) A few questions on the sonochemistry of solutions. Ultrason Sonochem 4: 211-215.

17. Tuulmets A (1997) Ultrasound and polar homogeneous reactions. Ultrason Sonochem 4: 189-193.

18. Mason TJ, Lorimer JP (1988) Sonochemistry, Theory Applications and Uses of Ultrasound in Chemistry, Ellis Horwood Ltd. JohnWiley and Sons, New York.

19. Omera BA, Barrowb D, Wirth T (2008) Effect of segmented fluid flow, sonications and phase - transfer catalysis on biphasic reactions in capillary microreactors. Chem Eng J 135S: S280-S283

20. Li JT, Chen GF, Xu WZ, Li TS (2003) The Michael reaction catalyzed by KF/ basic alumina under ultrasound irradiation. Ultrason Sonochem 10: 115-118.

21. Mason TJ (1997) Ultrasound in synthetic organic chemistry. Chem Soc Rev 26: $443-451$

22. Alonso F, Beletkaya IP, Yus M (2005) Non-conventional methodologies for transition-metal catalysed carbon-carbon coupling: a critical overview. Part 1 : The Heck reaction. Tetrahedron 61: 11771-11835.

23. Polácková V, Hut'ka M, Toma S (2005) Ultrasound effect on Suzuki reactions. 1. Synthesis of unsymmetrical biaryls. Ultrason Sonochem 12: 99-102.

24. Cravotto G, Palmisano G, Tollari S, Nano GM, Penoni A (2005) The Suzuk homocoupling reaction under high-intensity ultrasound. Ultrason Sonochem 12: 91-94.

25. Stavarache C, Pocsan AM, Vinatoru M, Mason TJ (2003)A comparison between the sonochemical and thermal reaction of $5 \mathrm{H}, 5 \mathrm{Cl}$-dibenz[a,d]cycloheptatriene with nitrobenzene. Ultrason Sonochem 10: 49-53.

26. Cella R, Stefani HA (2006) Ultrasound-assisted synthesis of $Z$ and $E$ stilbenes 
Citation: Selvaraj V, Harikumar K, Sathiyaraj M, Rajendran V (2015) Kinetic Investigation of Nitroarylation of Pyrrole with 1-Chloro-4-Nitrobenzene Using a New Multi-Site Phase-Transfer Catalyst under Ultrasonic Condition. Chem Sci J 6: 104. doi:10.4172/2150-3494.1000104

Page 8 of 8

by Suzuki cross-coupling reactions of organotellurides with potassium organotrifluoroborate salts. Tetrahedron 62: 5656-5662.

27. Atobe M, Kado Y, Asami R, Fuchigami T, Nanoka T (2005) Ultrasonic effects on electroorganic processes. Part 25 , Stereoselectivity control in cathodic debromination of stilbene dibromides. Ultrason Sonochem 12: 1-5.

28. Bougrin K, Lamiri M, Soufiaoui M (1998) Synthese "one pot" derives Isoxazoliniques par Activation Sonochimique. Tetrahedron Lett 39: 4455-4458.

29. Cains PW, Martin PD, Price CJ (1998) The use of ultrasound in industrial chemical synthesis and crystallization-1. Applications to synthetic chemistry. Org Proc Res Dev 2: 34-48.

30. Wang ML, Rajendran V (2006) A kinetic study of thioether synthesis under influence of ultrasound assisted phase-transfer catalysis conditions. J Mol Catal A: Chem 244: 237-243.

31. Masuno MN, Young DM, Hoepker AC, Skeeper CK, Molinski TF (2005) Addition of $\mathrm{Cl} 2 \mathrm{C}$ : to (-)-O-menthyl acrylate under sonication - phase - transfer catalysis. Efficient synthesis of (+)- and (-)-(2-chlorocyclopropyl)methanol, J Org Chem 70: 4162-4165

32. Wang ML, Rajendran V (2007) Ultrasound assisted phase-transfer catalytic epoxidation of 1,7-octadiene - a kinetic study. Ultrason Sonochem 14: 46-54.

33. Yang HM, Peng GY (2010) Ultrasound-assisted third-liquid phase-transfer catalyzed esterification of sodium salicylate in a continuous two-phase-flow reactor. Ultrason Sonochem 17: 239-245.

34. Saïd K, Moussaoui Y, Kammoun M, Ben Salem R (2011) Ultrasonic activation of Heck type reactions in the presence of Aliquat-336. Ultrason Sonochem 18: 23-27.

35. Wang ML, Chen CJ (2010) Kinetic Study of Synthesizing 1-(3-Phenylpropyl) pyrrolidine-2,5-dione under solid-liquid phase-transfer catalytic conditions assisted by ultrasonic irradiation, Org Process Res Dev 14: 737-745.

36. Yang HM, Li CC (2006) Kinetics for synthesizing benzyl salicylate by third-liquid phase-transfer catalysis, J Mol Catal A: Chem 246: 255-262.

37. Rabonivitz M, Sasson Y, Halpern M (1983) Hydroxide ion initiated reactions under phase-transfer-catalysis conditions-5. Isomerization of allybenzene via hydroxide ion extraction. J Org Chem 48: 1022-1025

38. Bhatkhande BS, Adhikari MV, Samant SD (2002) Sonochemical chlorooxidation of phenols using $\mathrm{HCl}-\mathrm{H} 2 \mathrm{O} 2$. Ultrason Sonochem 9: 31-35.

39. Margulis MA (2004) Sonochemistry as a new promising area of high energy chemistry, High Energ Chem 38: 135-142.
40. Mason TJ, Orimer JP (2002) Applied Sonochemistry: The Uses of Power Ultrasound in Chemistry and Processing, Wiley-VCH, Verlag, Weinheim. p.303.

41. Ambulgekar GV, Bhanage BM, Samant SD (2005) Low temperature recyclable catalyst for Heck reactions using ultrasound, Tetrahedron Lett 46: 2483-2485.

42. Wang ML, Rajendran V (2007) Ethoxylation of p-chloronitrobenzene using phase-transfer catalysts by ultrasound irradiation: a kinetic study. Ultrason Sonochem 14: 368-374.

43. Lepoint T, Mullie F (1994) What exactly is cavitation chemistry? Ultrason Sonochem 1: S13-S22.

44. Halpern M, Sasson Y, Rabinovitz M (1984) Hydroxide-ion initiated reactions under phase-transfer catalysis conditions. 6. Dehydrobromination of (2-bromoethyl) benzene via slow hydroxide-ion extraction J Org Chem 49: 2011-2012.

45. Kruus P, Burk RC, Entezari MH, Otson R (1997) Sonication of aqueous solutions of chlorobenzene. Ultrason Sonochem 4: 229-233.

46. Entezari MH, Heshmati A, Sarafraz-Yazdi A (2005) A combination of ultrasound and inorganic catalyst: removal of 2-chlorophenol from aqueous solution Ultrason Sonochem 12: 137-141.

47. Sasson Y, Bilman N (1989) Mechanism of solid/liquid phase - transfer catalysis in the presence of potassium carbonate: Alkylation of 2-pyrrolidinone, J Chem Soc Perkin Trans 2: 2029-2033.

48. Wang ML, Rajendran V (2007) Kinetics for dichlorocyclopropanation of 1,7 octadiene under the influence of Ultrasound assisted phase-transfer catalysis condition, J Mol Catal A: Chem 273: 5-13.

49. Landini D, Maia A, Rampoldi A (1986) Extractability and reactivity of hydroxide ion in low-polarity media under phase-transfer catalysis conditions: dramatic effect of the aqueous base concentration, J Org Chem 51: 5475-5476.

50. Chiellini E, Solaro R, Antone SD (1980) Heterogeneous ethylation of phenylacetonitrile, J Org Chem 45: 4179-4183.

51. Wang ML, Lee ZF (2006) Reaction of 4,4'-bis (chloromethyl)-1,1'-biphenyl and phenol in two-phase medium via phase-transfer catalysis, J Mol Catal A: Chem 264: $119-127$

52. Mahamuni NN, Gogate PR, Pandit AB (2006) Ultrasonic synthesis of benzaldehyde from benzyl alcohol using $\mathrm{H} 2 \mathrm{O} 2$ : Role of Ultrasound, Ind Eng Chem Res 45: 98-108.

53. Bussemaker MJ, Zhang D (2014) A phenomenological investigation into the opposing effects of fluid flow on sonochemical activity at different frequency and power settings. 1. Overhead stirring. Ultrason Sonochem 21: 436-445. 